\title{
Exploring the feasibility of on-site earthquake early warning using close-in records of the 2007 Noto Hanto earthquake
}

\author{
Yih-Min $\mathrm{Wu}^{1}$ and Hiroo Kanamori ${ }^{2}$ \\ ${ }^{1}$ Department of Geosciences, National Taiwan University, Taipei, Taiwan \\ ${ }^{2}$ Seismological Laboratory, California Institute of Technology, Pasadena, CA, USA
}

(Received June 22, 2007; Revised August 25, 2007; Accepted September 11, 2007; Online published February 19, 2008)

\begin{abstract}
In view of the remarkable success of the Japan Meteorological Agency earthquake early warning system (developed jointly with the National Research Institute for Earth Science and Disaster Prevention) during the 2007 Noto Hanto earthquake, we explore the use of an on-site early warning method with the hope of eventually enhancing the existing system for more robust and faster warning. We determined two early warning parameters $\tau_{c}$ and $P d$ using the K-NET and KiK-net data for the 2007 Noto Hanto earthquake as well as 20 large earthquakes in Japan. An extended method suggests a possibility of using the initial displacement amplitude data for faster warning. For the two nearby sites at the epicentral distances of 7 and $19 \mathrm{~km}$ of the 2007 Noto Hanto earthquake, an early warning can be ideally issued at 2.27 and $5.46 \mathrm{~s}$, respectively, before the peak ground motion velocity occurs at the site.
\end{abstract}

Key words: Earthquake early warning, magnitude, seismic hazard mitigation, $P$-waves.

\section{Introduction}

Several earthquake early warning methods have been recently developed, and some of them have been already implemented either experimentally or for actual operation. In particular, the systems developed at the National Research Institute for Earth Science and Disaster Prevention (NIED) (Horiuchi et al., 2005) and the Japan Meteorological Agency (JMA) (Tsukada et al., 2004) were integrated in June, 2005. JMA started official distribution of early warning information to a limited number of organizations in August, 2006, and plans to distribute it to the public in the fall of 2007. This system includes on-site warning capability using the amplitude and the temporal variation of acceleration at a single station. The system was successfully activated during the 2007 Noto Hanto (Peninsula) and the 2007 Niigata Chuetsu-Oki earthquakes, and provided accurate information regarding the source location, magnitude and intensity at about $3.8 \mathrm{~s}$ after the arrival of $P$ wave at nearby stations. This information reached the sites further than about $30 \mathrm{~km}$ from the epicenter as "early" warning (i.e., information arrived before shaking started at the site). This is a remarkable performance of the system for inland (or close to the shore) damaging earthquakes and gave promise of an early warning system as a practical means for earthquake damage mitigation. Although the warning did not reach close-in sites in time (i.e., the information arrived after shaking began) within about $30 \mathrm{~km}$ from the epicenter where such warnings are most needed, this is inevitable with the current density and configuration of the network. If the network is made denser in the future, the warning can be

Copyright (c) The Society of Geomagnetism and Earth, Planetary and Space Sciences (SGEPSS); The Seismological Society of Japan; The Volcanological Society of Japan; The Geodetic Society of Japan; The Japanese Society for Planetary Sciences; TERRAPUB. issued more rapidly and the information will be more useful and practical.

For any warning system, reliability is always important and it is desirable to have redundancy built in the system to make it more robust. In this paper, we explore the feasibility of using on-site early warning methods to increase the speed and reliability of the warning system. In on-site methods, the information from the initial part (up to a few seconds) of $P$ wave is used to estimate the magnitude and the strength of the impending ground motion at the same site. This method was initially developed for the Japanese Railway's Urgent Earthquake Detection and Alarm System (UrEDAS) (Nakamura, 1984, 1988) and, with some modifications, has been tested in Taiwan (Wu and Kanamori, 2005a) and southern California (Allen and Kanamori, 2003; Wu et al., 2007).

\section{Method}

Since the method has been described in detail elsewhere (Kanamori, 2005; Wu and Kanamori, 2005a), we only briefly summarize it below. We use high-pass $(0.075 \mathrm{~Hz})$ filtered vertical component ground-motion displacement records to compute two parameters $\tau_{c}$ and $P d$ from a short record with a duration $t_{0}$ (usually $3 \mathrm{~s}$ ) after the arrival of $P$ wave. Parameter $\tau_{c}$ characterizes the period of ground motion during the initial $t_{0}$ sec after the $P$ arrival, and $P d$ is the maximum displacement amplitude during the same time interval. The high-pass filter is applied to remove the drift of the displacement records after double integration of the accelerograms (e.g., Kanamori et al., 1999). As shown in Appendix 1 (Fig. A.1), the high-pass filter tends to reduce $P d$, especially for large events. Thus, the relationships involving these parameters depend on the specific filter used, and it is important to use the same filter consistently. 
Table 1. Parameters of the twenty events used in this study.

\begin{tabular}{lcccccc}
\hline Name of event & Origin time & $\begin{array}{c}\text { Lat. } \\
(\mathrm{N})\end{array}$ & $\begin{array}{c}\text { Long. } \\
(\mathrm{E})\end{array}$ & $\begin{array}{c}\text { Depth } \\
(\mathrm{km})\end{array}$ & $\begin{array}{c}M_{\mathrm{w}} \\
\tau_{c} \\
(\mathrm{~s})\end{array}$ \\
\hline Hyuganada & $1996 / 12 / 0222: 18: 06$ & 31.783 & 131.633 & 35 & 6.7 & $2.151 \pm 0.418$ \\
Kagoshima & $1997 / 03 / 2608: 31: 53$ & 31.983 & 130.367 & 8 & 6.1 & $1.619 \pm 0.396$ \\
Kagoshima & $1997 / 05 / 1305: 38: 32$ & 31.950 & 130.300 & 8 & 6.0 & $1.075 \pm 0.458$ \\
Nii-jima-Kozu-shima & $2000 / 07 / 1501: 30: 35$ & 34.423 & 139.253 & 5 & 6.0 & $1.392 \pm 0.423$ \\
Western-Tottori & $2000 / 10 / 0604: 30: 25$ & 35.275 & 133.348 & 11 & 6.7 & $1.462 \pm 0.515$ \\
Geiyo & $2001 / 03 / 2406: 28: 02$ & 34.123 & 132.705 & 51 & 6.8 & $1.785 \pm 0.818$ \\
Miyagi-Oki & $2003 / 05 / 2609: 24: 39$ & 38.808 & 141.678 & 71 & 7.0 & $2.438 \pm 0.909$ \\
Tokachi-Oki & $2003 / 09 / 2519: 50: 38$ & 41.778 & 144.078 & 42 & 8.3 & $4.399 \pm 1.198$ \\
Tokachi-Oki (aftershock) & $2003 / 09 / 2521: 08: 19$ & 41.707 & 143.695 & 21 & 7.3 & $2.912 \pm 1.104$ \\
Kii-Hanto-Oki & $2004 / 09 / 0510: 07: 16$ & 33.028 & 136.800 & 38 & 7.2 & $3.343 \pm 0.409$ \\
Kii-Hanto-Oki & $2004 / 09 / 0514: 57: 43$ & 33.143 & 137.142 & 44 & 7.4 & $3.107 \pm 0.908$ \\
Chuetsu & $2004 / 10 / 2308: 56: 05$ & 37.288 & 138.870 & 13 & 6.6 & $2.738 \pm 1.112$ \\
Chuetsu (aftershock) & $2004 / 10 / 2309: 03: 16$ & 37.350 & 138.985 & 9 & 6.1 & $1.985 \pm 0.556$ \\
Chuetsu (aftershock) & $2004 / 10 / 2309: 34: 10$ & 37.303 & 138.932 & 14 & 6.3 & $1.622 \pm 0.795$ \\
Kushiro-Oki & $2004 / 11 / 2818: 32: 19$ & 42.943 & 145.278 & 48 & 7.0 & $3.480 \pm 0.638$ \\
Fukuoka-Oki & $2005 / 03 / 2001: 53: 47$ & 33.735 & 130.177 & 9 & 6.6 & $1.134 \pm 0.508$ \\
Miyagi-Oki & $2005 / 08 / 1602: 46: 40$ & 38.147 & 142.282 & 42 & 7.2 & $2.143 \pm 0.638$ \\
Oita & $2006 / 06 / 1120: 01: 31$ & 33.133 & 131.407 & 146 & 6.4 & $1.453 \pm 0.673$ \\
Noto-Hanto-Oki & $2007 / 03 / 2500: 41: 57$ & 37.221 & 136.686 & 11 & 6.7 & $2.331 \pm 1.382$ \\
Chuetsu-Oki & $2007 / 07 / 1601: 13: 30$ & 37.557 & 138.608 & 17 & 6.6 & $2.243 \pm 0.307$ \\
\hline
\end{tabular}

The period parameter $\tau_{c}$ is computed by

$$
\tau_{c}=2 \pi / \sqrt{\left[\int_{0}^{t_{0}} \dot{u}^{2}(t) d t\right] /\left[\int_{0}^{t_{0}} u^{2}(t) d t\right]},
$$

where $u$ is the high-pass filtered displacement of the vertical component ground motion. $\tau_{c}$ approximately represents the $P$ wave pulse width which increases with the magnitude and can be used to estimate the event magnitude. Wu and Kanamori (2005b) showed that $P d$ can be used to estimate the peak ground motion velocity (PGV) at the same site. $\tau_{c}$ and $P d$ are the two basic parameters used in on-site warning.

\section{Analysis}

Wu and Kanamori (2005b) and Wu et al. (2007) showed that $\tau_{c}$ and $P d$ are useful for estimating the magnitude and peak ground motion, respectively, for earthquakes in Taiwan and southern California.

Since no systematic analysis of $\tau_{c}$ and $P d$ has been made for large Japanese earthquakes, we first present general relationships between $\tau_{c}$ and magnitude, and $P d$ and peak ground-motion velocities, PGV, determined with the data from K-NET and KiK-net of NIED. Table 1 lists the 20 events we studied. The 2007 Noto Hanto and the $2007 \mathrm{Ni}$ igata Chuetsu-Oki earthquakes are included. These relationships provide a basic framework for on-site early warning. Then, in an effort to explore the feasibility of very rapid warning, we will investigate the use of $P d$ in more detail for the Noto Hanto earthquake.

\section{4. $\tau_{c}$ vs. $M$ and PGV vs. $P d$ Relationships}

The results for $\tau_{c}$ are summarized in Table 1 and Fig. 1, and the results for $P d$ are shown in Fig. 2(a). Three events deeper than $50 \mathrm{~km}$ are also included. The peak ground motion velocities are computed from the horizontal components of K-NET data and from the surface stations of KiK-net. The larger of the two horizontal components is

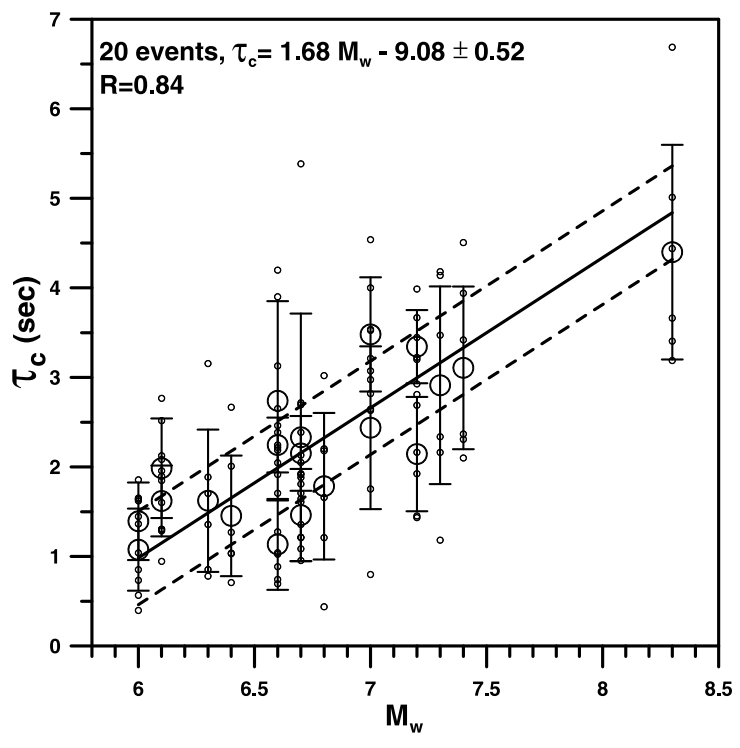

Fig. 1. $\tau_{c}$ estimates for 20 events using the nearest 6 stations of K-NET and KiK-net. Small open circles show single-record results and large circles show the event-average. Solid line shows the least squares fit and the two dashed lines show the range of one standard deviation.

used to determine PGV. In general, the results are consistent with those determined earlier for Taiwan and southern California. Rydelek and Horiuchi (2006) determined a period-parameter similar to $\tau_{c}$ for large Japanese events with a magnitude range $6 \leq M \leq 8$ using the Hi-net data. Since the period-parameter they used and the method are different from those we used, our results cannot be directly compared with theirs. However, as shown in Appendix 2, if we apply our method to their data set the results from the two studies are compatible.

The $P d$ values for Japanese earthquakes are on the same trend as those for earthquakes in Taiwan and southern California, but the scatter for the Japanese data is considerably large. We noticed that $P d 3$ values (the last digit indicates the duration over which $P d$ is measured) for some events 

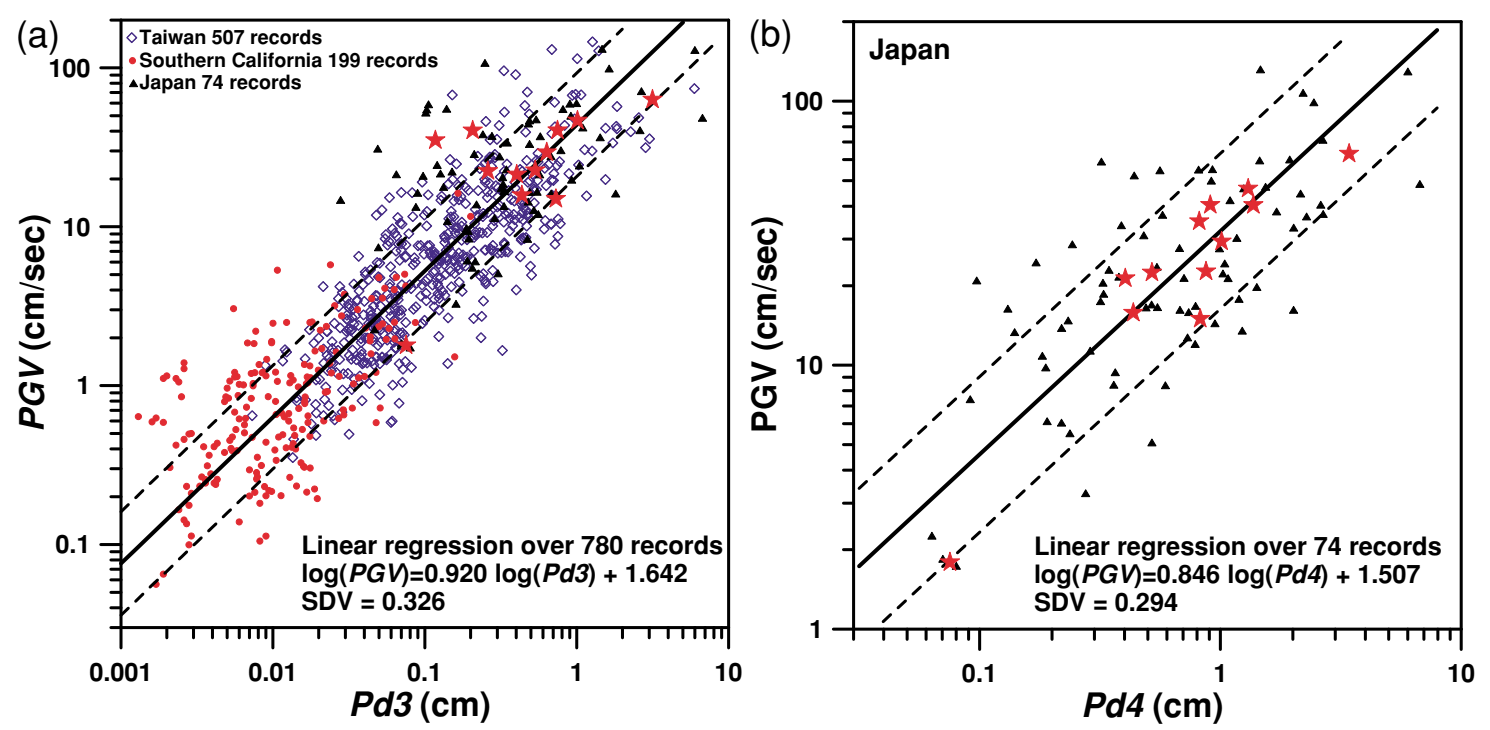

Fig. 2. (a) Relationship between peak initial three-second displacement amplitude ( $P d 3$ ) and peak ground velocity (PGV) for 780 records with the epicentral distances less than $30 \mathrm{~km}$ for Japan (black triangles), southern California (red solid circles) and Taiwan (blue diamonds). Red stars indicate the event-average of the Japanese data. Solid line indicates the least squares fit and the two dashed lines show the range of one standard deviation. (b) Relationship between peak initial four-second displacement amplitude ( $P d 4)$ and PGV. Red stars indicate the event-average of the Japanese data. Solid line indicates the least squares fit and the two dashed lines show the range of one standard deviation.

Table 2. Parameters of station locations, $\tau_{c}, P d$, PGA and PGV measurements of the 2007 Noto Hanto earthquake.

\begin{tabular}{cccccccccc}
\hline Station & $\begin{array}{c}\text { Distance } \\
(\mathrm{km})\end{array}$ & $\begin{array}{c}\tau_{c} \\
(\mathrm{~s})\end{array}$ & $\begin{array}{c}P d 3 \\
(\mathrm{~cm})\end{array}$ & $\begin{array}{c}P d 4 \\
(\mathrm{~cm})\end{array}$ & $\begin{array}{c}t_{-} P d \geq 0.5 \\
(\mathrm{~s})\end{array}$ & $\begin{array}{c}\text { PGV } \\
(\mathrm{cm} / \mathrm{s})\end{array}$ & $\begin{array}{c}t \_ \text {PGV } \\
(\mathrm{s})\end{array}$ & $\begin{array}{c}t_{\text {PGA }} \\
\left(\mathrm{cm} / \mathrm{s}^{2}\right)\end{array}$ \\
\hline ISK006 & 7 & 5.39 & 6.73 & 6.73 & 0.54 & 48.56 & 2.81 & 848.99 \\
$(\mathrm{~s})$
\end{tabular}

with relatively large PGV are very small. Inspection of the seismograms revealed that for these records the initial $P$ wave amplitude is very small, but increases rapidly after that. Thus, if we increase the time window from 3 to $4 \mathrm{sec}$, the scatter of the PGV vs. Pd4 diagram is significantly reduced as shown in Fig. 2(b), and the trend for the Japanese data is similar to that of the Taiwan data. A similar sensitivity of magnitude vs. $P d$ scaling to the duration of the time window is reported by Zollo et al. (2007). This observation seems to reflect the complexity of the nucleation process of earthquakes: the growth rate of the initial rupture seems to vary considerably for different events. This complexity is inherent to earthquake rupture pattern and some uncertainties are inevitable. The large scatter can be also due to site response. If we take the event average, the overall trend is approximately the same as that for the Taiwan data (Fig. 2(b)).

\section{The 2007 Noto Hanto Earthquake}

We now discuss the result for the 2007 Noto Hanto earthquake in detail. This earthquake $\left(M_{\mathrm{w}}=6.7\right)$ occurred at 09:41 a.m., March 25, 2007 (local time) (00:41 a.m. UT), and is located at $37.221^{\circ} \mathrm{E}, 136.686^{\circ} \mathrm{E}$, and depth $=10.7 \mathrm{~km}$. Table 2 lists the stations used and the measured values of $\tau_{c}, P d$ and $\mathrm{PGV}$ at each station. Except for the nearest $(\Delta=7 \mathrm{~km})$ station, ISK006, the values of $\tau_{c}$ are generally consistent. As shown in Fig. 3, the near-field displacement dominated at the station ISK006. Because of the ramp-like displacement of the near-field, it yielded an anomalously large $\tau_{c}$. This would result in an anomalously large estimate of magnitude. We did not encounter this problem for any other records from the events listed in Table 1 . Thus, the occurrence of this problem is considered very rare. Nevertheless, this can cause a problem if we are to use the specific value of magnitude estimated from each station for early warning. However, as shown in Table 2 , since the $\tau_{c}$ values estimated from other stations are normal, if we take the median of the $\tau_{c}$ values as a representative value of magnitude for the group of stations, or if we introduce a scheme to remove outliers, this problem can be alleviated. Also, if the warning is to be issued as a threshold warning (i.e. a warning with a minimum magnitude) as discussed in Kanamori (2005) and Wu et al. (2007), this will not cause a serious problem. In any case, this is the problem we encountered and should be borne in mind in using onsite warning methods. The effect of the near-field displacement is also evident in $P d$. Again, we can take the same procedure as we discussed above for $\tau_{c}$ to alleviate the problem.

\section{Extension of the Method for Faster Warning}

In the method we discussed above we used a record with a duration of $3 \mathrm{~s}$ (i.e., $t_{0}=3 \mathrm{~s}$ ) after the $P$-wave arrival, 

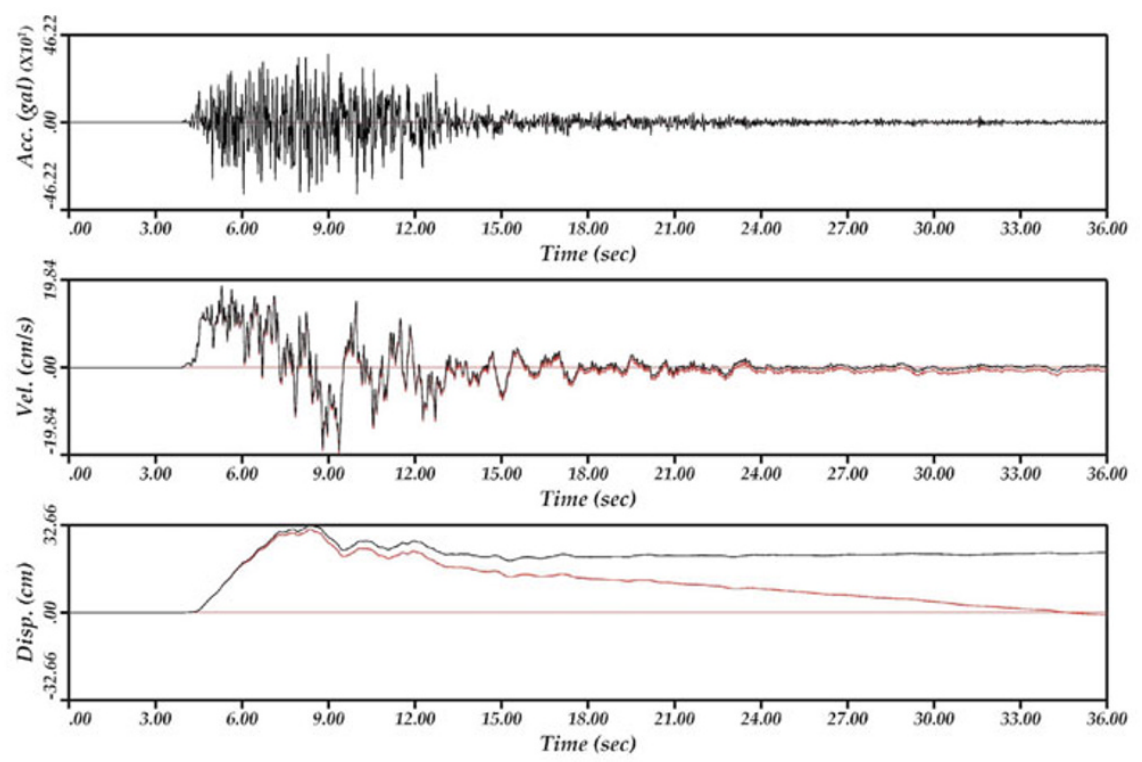

Filename $=$ ISK0060703250942.UD, V Component Disp. $=21.79+-1.11 \mathrm{~cm}$

Fig. 3. Acceleration, velocity, and displacement (unfiltered) at station ISK006 ( $\Delta=7 \mathrm{~km})$. Note a ramp-like velocity waveform caused by near-field displacement. Red and black lines show raw and corrected traces, respectively.

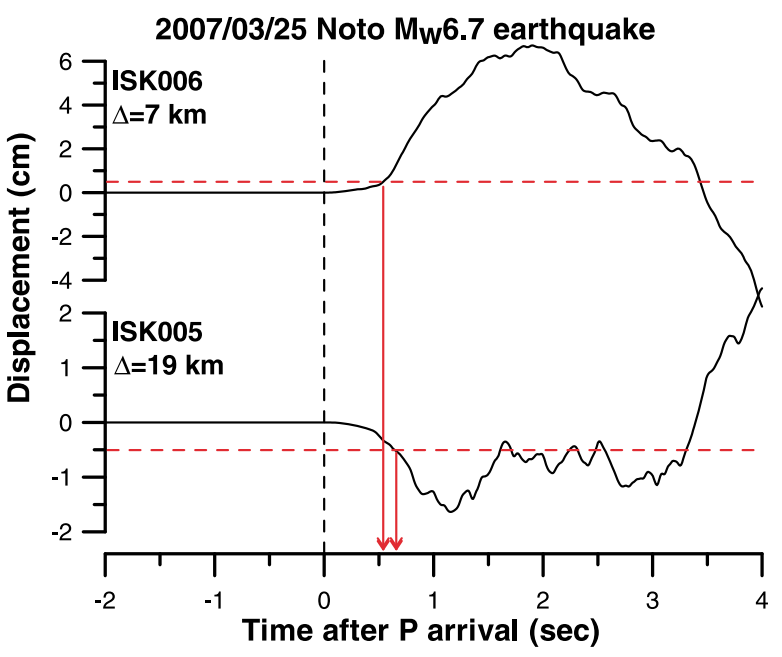

Fig. 4. Filtered displacement seismograms of the two nearest K-Net stations. Horizontal dashed lines are drawn at the threshold value of $P d=0.5 \mathrm{~cm}$. Vertical arrows indicate the time when the threshold is reached. If a warning is issued at this time, the warning can be issued at about 0.54 and $0.64 \mathrm{~s}$ after the $P$ arrival time at stations ISK006 and ISK005, respectively.

which means that it will take at least $3 \mathrm{~s}$ after the arrival of $P$ wave before we can issue a warning. Since the present JMA system can perform nearly as fast, the on-site method described here itself does not have advantage over the JMA system as far as the warning time is concerned. However, the on-site method described here provides redundancy desirable for any warning system.

One possible approach toward issuing faster warning is to monitor the high-pass filtered ground motion displacement, and issue a warning as soon as it has exceeded a threshold value. From our experience with the Taiwan and southern California data, if $P d$ exceeds $0.5 \mathrm{~cm}$, the $P G V$ at the site

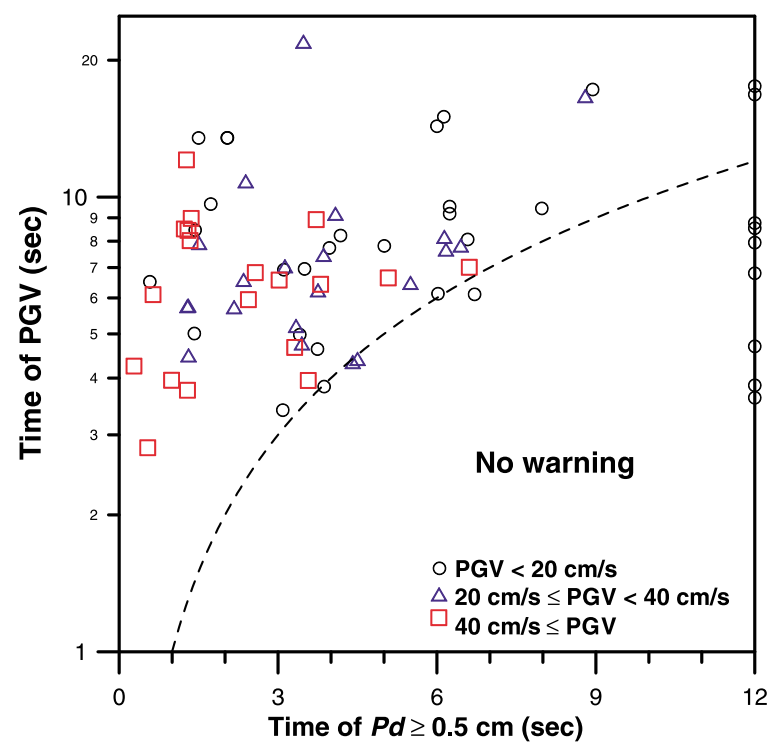

Fig. 5. Illustration of an on-site early warning scheme. The time (after $P$ arrival) when $P d$ exceeds $0.5 \mathrm{~cm}$ (denoted by $t_{-} P d \geq 0.5$ in the text) is on the horizontal axis, and the time (after $P$ arrival) when PGV occurs (denoted by $t_{-} \mathrm{PGV}$ in the text) is on the vertical axis. The open circles plotted at $t_{-} P d \geq 0.5=12 \mathrm{~s}$ indicates the events for which $P d$ never reached the threshold value, $0.5 \mathrm{~cm}$.

most likely exceeds the damaging level, i.e., $20 \mathrm{~cm} / \mathrm{s}$. As shown in Fig. 4, for the 2007 Noto Hanto earthquake, at the two nearest stations, ISK006 $(\Delta=7 \mathrm{~km})$ and ISK005 $(\Delta=19 \mathrm{~km})$, the threshold value of $P d=0.5 \mathrm{~cm}$ was reached at $0.54 \mathrm{~s}$, and $0.64 \mathrm{~s}$, respectively, from the arrival of $P$ wave. If we are to issue an onsite warning at a threshold of $P d \geq 0.5 \mathrm{~cm}$, then at the site ISK006 and ISK005, an warning will be issued at $0.54 \mathrm{~s}$ and $0.64 \mathrm{~s}$ after the $P$ arrival, respectively, which are $2.27 \mathrm{~s}$ and $5.46 \mathrm{~s}$ before PGA occurs at the respective sites (Table 2) and the early warn- 
ing system becomes effective even at close-in sites where warnings are most needed. So far we have experienced only a very few cases in which $P d$ exceeded $0.5 \mathrm{~cm}$ within $3 \mathrm{sec}$ after $P$ arrival, and we need to accumulate more data to be able to determine the best threshold value for $P d$.

We tested this approach with other events. In this method, we monitor the filtered displacement after a $P$ trigger. When $P d$ exceeds a threshold value (e.g., $0.5 \mathrm{~cm}$ ), an alarm is issued. If this alarm is followed by a large PGV (e.g., $\geq 20 \mathrm{~cm} / \mathrm{s}$ ), then the alarm is successful; otherwise it is a false alarm. Then an important parameter is the difference between the time when $P d=0.5 \mathrm{~cm}$ is detected (denoted by $t_{-} P d \geq 0.5$ ), and PGV is detected (denoted by $t_{-} \mathrm{PGV}$ ). Figure 5 shows the result for the 74 records at distances shorter than $30 \mathrm{~km}$ of the events listed in Table 1 . For the case in which $t$ PGV is large (e.g., $>7 \mathrm{sec}$ ), we will have enough time to examine the data from other stations to update the warning. Figure 5 indicates that for $t_{-} \mathrm{PGV} \leq 7 \mathrm{~s}$, the alarms with $t_{-} P d \geq 0.5 \mathrm{~s}$ are successful (i.e., $P G V \geq 20 \mathrm{~cm} / \mathrm{s}$ ) 70 to $80 \%$ of the time. Considering the difficulty in issuing useful alarms at short distances, this success rate is satisfactory. For practical applications, we may have to modify the thresholds and method, but we hope that this approach will provide additional capability for short-distance warning.

\section{Conclusion}

We used the NIED K-NET and KiK-net data to determine two on-site earthquake early warning parameters $\tau_{c}$ and $P d$ for 20 large earthquakes in Japan. The results are overall consistent with those obtained earlier for earthquakes in Taiwan and southern California and demonstrate that $\tau_{c}$ and $P d$ are useful parameters for early warning in Japan. We explored extension of the method for faster threshold warning by monitoring the high-pass filtered ground motion amplitudes of the 2007 Noto Hanto earthquake. For the two nearby sites at epicentral distances of 7 and $19 \mathrm{~km}$, a warning can be issued before the peak ground motion velocity occurrs there. Thus, useful early warning can be issued to the epicentral area where such warning is most needed; this is an advantage of on-site warning, and the method will provide additional capability to the existing JMA system.

At present, the data from K-NET and KiK-net are not available real-time for early warning purposes. However, if the method illustrated in this paper proved useful, two options can be considered. One is to implement real-time telemetry for these networks and the other is to install a simple software to perform the onsite analysis at the station processor and send only warning information. In view of the remarkable success of the JMA system, we believe that further enhancement of the system like the one described here is worthwhile to make the overall system faster, more reliable, and robust.

Acknowledgments. We thank S. Horiuchi and the National Research Institute for Earth Science and Disaster Prevention for providing us with the KiK-net, K-NET data and Hi-net data used in this study. We thank Aldo Zollo and Shinya Tsukada for providing comments on the manuscript. This research was supported by the National Science Council, Republic of China.

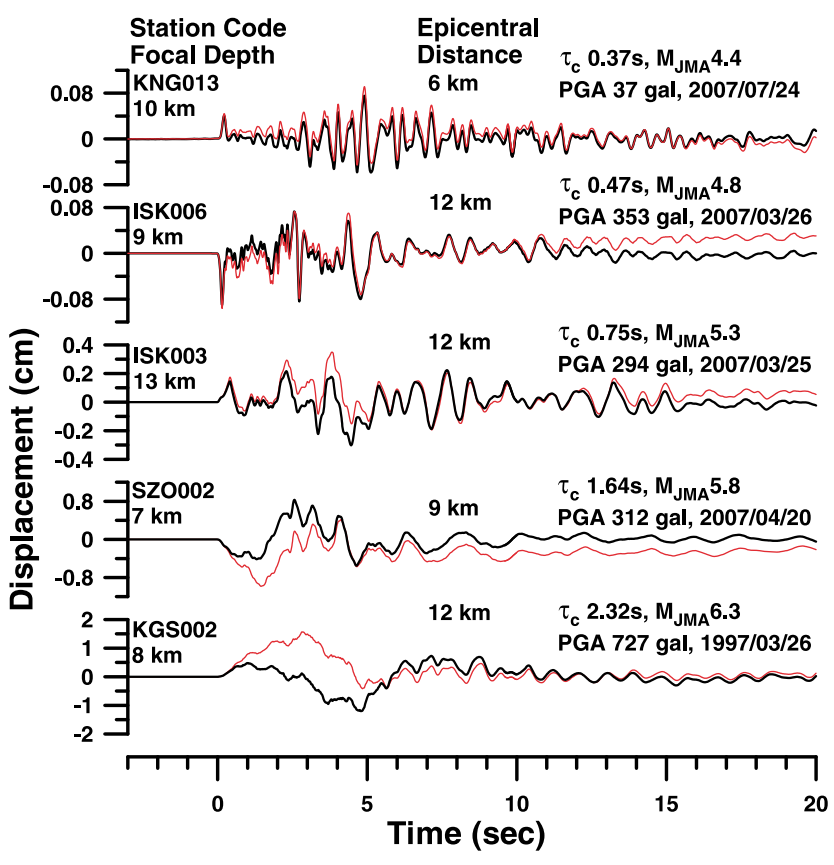

Fig. A.1. Comparison of the raw (red) and high-pass filtered (black) records.

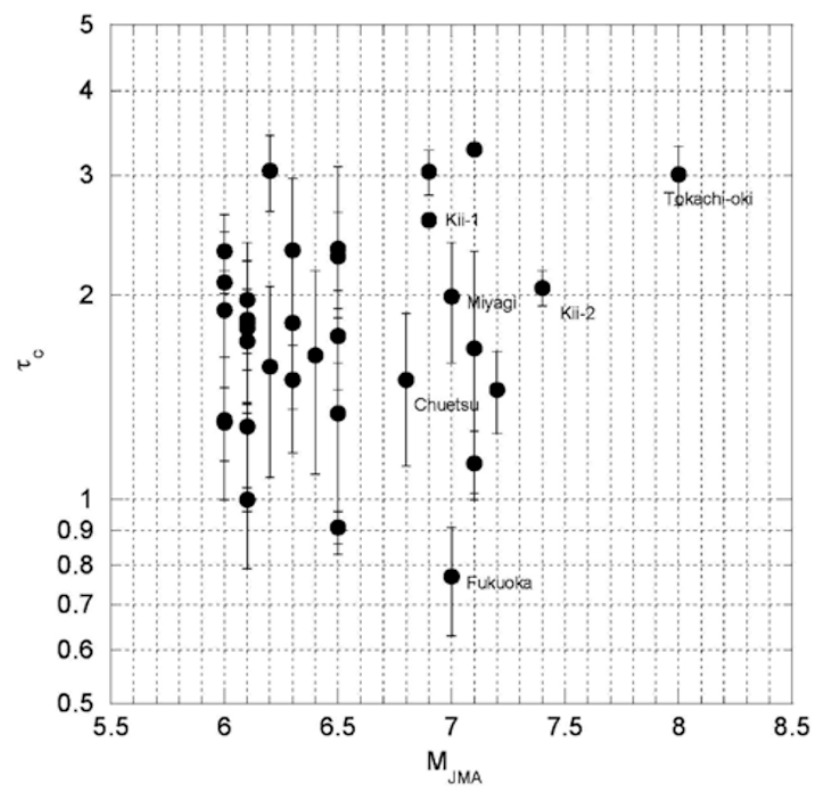

Fig. A.2. $\tau_{c}$ from Hi-net data computed with the method used in this paper.

\section{Appendix 1. The effect of high-pass filter on the displacement records}

The noise in the strong motion data at long period is always a critical issue. The noise level depends on the particular instrument type as well as the site condition. In our paper, we used a one-pass (i.e., causal) high-pass Butterworth filter which removes essentially everything below $0.075 \mathrm{~Hz}$ (about $13 \mathrm{~s}$ ). In this paper we used the method of applying a causal filter to on-line data discussed in Kanamori et al. (1999). Thus, the regression relations and the scaling relations used in this paper depend on the particular filter and the cut-off frequency used. A lower cut-off frequency is more desirable for larger earthquakes, but effect of the 


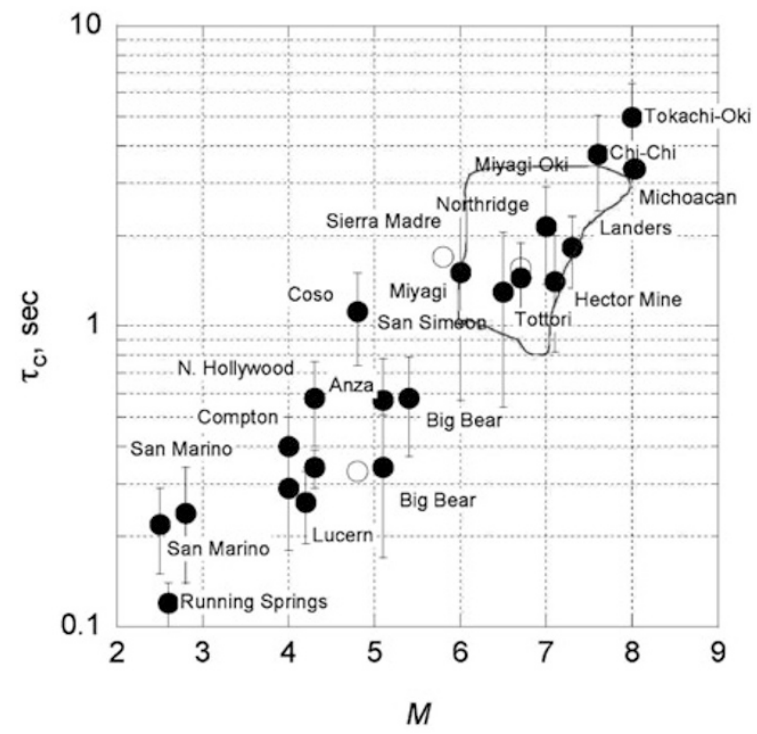

Fig. A.3. Comparison of the overall trend of the Hi-net results shown by red curve with the results obtained from earthquakes over a large magnitude range.

long-period noise increases. Considering this trade-off we empirically chose the cut-off frequency at $0.075 \mathrm{~Hz}$. Figure A.1 compares the filtered and raw displacement records.

\section{Appendix 2. Comparison with the results of Ry- delek and Horiuchi (2006)}

Rydelek and Horiuchi (2006) determined a periodparameter similar to $\tau_{c}$ for large Japanese events with a magnitude range $6 \leq M \leq 8$ using the Hi-net data. Since the period-parameter they used and the method are different from those we used, we cannot directly compare the results by the two studies.

The methods used in this paper and Rydelek and Horiuch (2006) (hereafter 260 referred to as RH) differ in two respects. 1) We use a fixed 3-sec window while RH used a sliding window originally used by Nakamura (1988). 2) As discussed in Kanamori (2005), we used $\dot{u}-u$ pairs while RH used $\ddot{u}$ - $\dot{u}$ pairs to compute the period parameters. Furthermore, if we use Hi-net data directly for $\ddot{u}$ and $\dot{u}$, as was presumably done by $\mathrm{RH}$, the meaning of $\tau_{c}$ becomes different. As discussed in Kanamori (2005), our $\tau_{c}$ is determined by the average of $f^{2}$ weighted by the square of the modulus of the displacement spectrum, while the period parameter used by $\mathrm{RH}$ is defined by the average of $f^{2}$ weighted by the square of the modulus of the (velocity spectrum)*(Hi-net response). Since the Hi-net response falls off very rapidly at frequencies below $1 \mathrm{~Hz}$, the combined effect of the velocity spectrum and the Hi-net response results in the period pa- rameter used by $\mathrm{RH}$ being weighted much more strongly by shorter period waves than our $\tau_{c}$. For this reason, as the period increases with magnitude, the period parameter tends to saturate. Thus, the relation between our $\tau_{c}$ and magnitude cannot be directly compared with that by RH. For comparison, we computed $\tau_{c}$ from Hi-net data after deconvolving the instrument response, and using our method (Fig. A.2).

For this small magnitude range, the dependence of $\tau_{c}$ on magnitude is not apparent, as pointed out by $\mathrm{RH}$, but as shown in Fig. A.3, if we compare the Hi-net results as a whole with those from other events (Kanamori, 2005), the over all trend determined from the Hi-net data is essentially consistent with the general trend. Thus, the correlation between $\tau_{c}$ and magnitude is ambiguous over a magnitude range from 6 to 8 , but we found no fundamental difference between our results obtained from KiK-net and K-net and that from Hi-net.

\section{References}

Allen, R. M. and H. Kanamori, The potential for earthquake early warning in Southern California, Science, 300, 786-789, 2003.

Horiuchi, S., H. Negishi, K. Abe, A. Kamimura, and Y. Fujinawa, An Automatic Processing System for Broadcasting Earthquake Alarms, Bull. Seism. Soc. Am., 95, 708-718, 2005.

Kanamori, H., Real-time seismology and earthquake damage mitigation, Annual Review of Earth and Planetary Sciences, 33, 195-214, doi:10.1146/annurev.earth.33.092203.122626, 2005.

Kanamori, H., E. Hauksson, and P. Maechling, Continuous monitoring of ground motion parameters, Bull. Seism. Soc. Am., 89, 311-316, 1999.

Nakamura, Y., Development of the earthquake early-warning system for the Shinkansen, some recent earthquake engineering research and practical in Japan, The Japanese National Committee of the International Association for Earthquake Engineering, 224-238, 1984.

Nakamura, Y., On the urgent earthquake detection and alarm system (UrEDAS), Proceeding of $9^{\text {th }}$ world conference on earthquake engineering, Tokyo-Kyoto, Japan, 1988.

Rydelek, P. and S. Horiuchi, Is earthquake rupture deterministic?, Nature, 442, E5-E6, 2006.

Tsukada, S., T. Odaka, K. Ashiya, K. Ohtake, and D. Zozaka, Analysis of the envelope waveform of the initial part of $\mathrm{P}$-waves and its application to quickly estimating the epicentral distance and magnitude, Zisin, 56, 351-361, 2004.

$\mathrm{Wu}$, Y. M. and H. Kanamori, Experiment on an onsite early warning method for the Taiwan early warning system, Bull. Seism. Soc. Am., 95, 347-353, 2005a.

$\mathrm{Wu}, \mathrm{Y}$. M. and H. Kanamori, Rapid assessment of damaging potential of earthquakes in Taiwan from the beginning of P Waves, Bull. Seism. Soc. Am., 95, 1181-1185, 2005b.

Wu, Y. M., H. Kanamori, R. Allen, and E. Hauksson, Determination of earthquake early warning parameters, $\tau_{c}$ and $P d$, for southern California, Geophys. J. Int., 170, 711-225, doi:10.1111/j.1365246X.2007.03430.x, 2007.

Zollo, A., M. Lancieri, and S. Nielsen, Peak ground displacement and earthquake magnitude: Reply, Geophys. Res. Lett., doi:10.1029/ 2007GL030560, 2007 (in press).

Y.-M. Wu (e-mail: drymwu@ntu.edu.tw) and H. Kanamori 